Check for updates

Cite this: RSC Adv., 2017, 7, 37534

\title{
Lipase-mediated synthesis of sugar-PEG-based amphiphiles for encapsulation and stabilization of indocyanine green $\dagger$
}

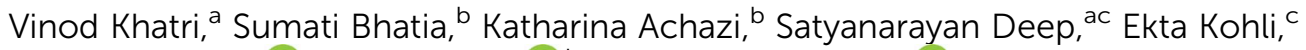 \\ Sunil K. Sharma, (D) ${ }^{a}$ Rainer Haag (D) ${ }^{b}$ and Ashok K. Prasad (D) *a
}

\begin{abstract}
Indocyanine green (ICG) is a near-infrared dye for wide-ranging applications, but its utility for biological studies is limited due to poor aqueous stability and concentration-dependent aggregation. Aqueous polymeric micelles/micellar aggregates of amphiphilic copolymers could be used to protect indocyanine green (ICG) by encapsulation, which is used in laser-mediated photothermal therapy (PTT) and photodynamic therapy (PDT). The sugar-PEG-based amphiphilic copolymers were synthesized using Novozym 435-catalyzed transesterification reaction under bulk conditions for encapsulation of ICG. A dye loading study revealed that micelles derived from copolymers having decanoylated and myristoylated sugar moieties encapsulate $62 \%$ and $92 \%$ of the ICG, respectively, with a multi-fold increase in its aqueous stability. Furthermore, an efficient internalization of micelles of acylated amphiphilic copolymers in aqueous medium was demonstrated by incubating cells with Nile redencapsulated amphiphiles.
\end{abstract}

Received 3rd May 2017

Accepted 20th July 2017

DOI: $10.1039 / \mathrm{c} 7 \mathrm{ra04994c}$

rsc.li/rsc-advances bioadhesive/targeting properties. ${ }^{25-28}$ Specifically, there have been reports of lectin proteins and other biomolecules with sugar molecules on the surface of micelles. ${ }^{29,30}$ Water-soluble, sugar-based polymers are now being routinely used to prolong drug circulation and residence time within affected cells. Further, it has been shown that nano-sized particles have a great potential in cancer therapy due to enhanced permeability and retention (EPR) effect. ${ }^{31}$ Herein, we report the synthesis of novel sugar-PEG-based amphiphilic copolymers in solvent-free conditions using Novozym 435 as a catalyst. The encapsulation and aqueous stability of the encapsulated ICG dye was determined in the micelles of amphiphilic copolymers by fluorescence measurements at $20{ }^{\circ} \mathrm{C}$ and at $37^{\circ} \mathrm{C}$. The Nile red fluorescent dye was used for the cellular uptake study of micelles in A549 cells.

\section{Experimental}

\subsection{Materials}

Dry reactions were carried out under a nitrogen atmosphere. Analytical TLCs were performed on pre-coated Merck silica-gel 60F254 plates, and silica gel (100-200 mesh) was used for column chromatography. All materials and reagents were commercially available and used without further purification. For polymerization reaction poly[ethylene glycol bis(carboxymethyl)ether]diethyl ester and sugar monomers 2,5-anhydro-Dmannitol (1) and 2,5-anhydro-3,4-di-O-benzyl-D-mannitol (2) were dried under vacuum for $10 \mathrm{~h}$ prior to use. Dialysis membrane (MWCO 1.2-2 kDa), Novozym 435 and Nile red were 
purchased from Sigma-Aldrich Pvt. Ltd. The cell line A549 was purchased from DMSZ, Germany (Catalogue no. ACC107). Milli$\mathrm{Q}$ water was used for encapsulation and physicochemical characterization experiments.

\subsection{Instrumentations and methods}

Molecular weight and molecular-weight distribution of copolymers were recorded by gel permeation chromatography (GPC) equipped with an Agilent 1100 pump, refractive index detector, and Suprema columns. THF was used as eluent with a flow rate of $1 \mathrm{~mL} \mathrm{~min}^{-1}$. Calibration of molecular weights was done using polystyrene as a standard. Surface tension of copolymers was determined by the pendent drop tensiometer OCA 20 for calculating the critical aggregation concentration (CAC) values. Samples were prepared in Milli-Q water $24 \mathrm{~h}$ before measurement. For the surface tension measurement, first a stock solution of $1 \mathrm{mM}$ concentration was prepared and then samples were prepared by the half-dilution method. The aggregation behavior of copolymers was studied over a concentration range of $10^{-3}$ to $10^{-7} \mathrm{M}$. Measurement was stopped when surface tension did not change. Equilibrium was maintained generally for $40-60 \mathrm{~min}$ at $20^{\circ} \mathrm{C}$. The size of micelles/micellar aggregates was determined by dynamic light scattering (DLS) using a Zetasizernano ZS analyzer, a Malvern instrument equipped with a $633 \mathrm{~nm}$ laser at a scattering angle of $173^{\circ}$. The measurement was performed at $25{ }^{\circ} \mathrm{C}$ after diluting the samples at an appropriate concentration in Milli-Q water. Solutions were filtered via $0.2 \mu \mathrm{m}$ polytetrafluoroethylene (PTFE) filters and the samples were allowed to equilibrate for $4 \mathrm{~h}$ at $20^{\circ} \mathrm{C}$. All experiments were done with disposable transparent cuvettes. Images of micelles formed were obtained by transmission electron microscope (TEM) using a Jeol JEM-2100F instrument that accelerated at $200 \mathrm{kV}$. Samples were prepared by dipping a carbon-coated copper grid into a copolymer solution. The grid was blotted with filter paper, which was followed by staining with $1 \%$ phosphotungustic acid (PTA). The copper grid loaded with micelles was dried at room temperature before the images were taken. Absorbance spectra were recorded between 250900 nm using a Scinco S-3150 UV-visible spectrophotometer. All measurements were carried out with a disposable, transparent UV cuvette. The fluorescence spectra were determined on both native ICG and formulated ICG using a Jasco FP-6500 spectrofluorometer equipped with a thermostatic cell holder and a DC-powered $150 \mathrm{~W}$ xenon lamp. For fluorescence, excitation was done at $780 \mathrm{~nm}$ and emission was recorded from 790$900 \mathrm{~nm}$. Origin 6.1 software was used for plotting the graphs.

\subsection{Synthesis of copolymers $3-7$}

2.3.1. Procedure for synthesis of copolymer 3. PEG-600 diethyl ester (3.69 g) and 2,5-anhydro-D-mannitol (0.9 g) were placed in a $50 \mathrm{~mL}$ round-bottom flask and allowed to stir at $70{ }^{\circ} \mathrm{C}$ for $5 \mathrm{~min}$ to make the homogenous mixture. To this mixture, Novozym 435 (459 mg, 10\% by weight of monomers) was added and the reaction flask was maintained at $70{ }^{\circ} \mathrm{C}$ under vacuum. The reaction was allowed to proceed for $48 \mathrm{~h}$ and then quenched by adding methanol and filtering off the enzyme. The organic phase was dialyzed in the dialysis tube with MWCO 1.2$2.0 \mathrm{kDa}$ against methanol for $48 \mathrm{~h}$ to obtain copolymer 3 .

Copolymer 3 was obtained as viscous oil in $70 \%$ yield; ${ }^{1} \mathrm{H}$ NMR (500 MHz, $\left.\mathrm{CD}_{3} \mathrm{OD}, \delta(\mathrm{ppm})\right): 1.26$ (t, $\left.J=7.0 \mathrm{~Hz}, 3 \mathrm{H}\right), 3.62-$ $3.70(\mathrm{~m}, 474 \mathrm{H}), 3.76-3.99(\mathrm{~m}, 34 \mathrm{H}), 4.15-4.41(\mathrm{~m}, 75 \mathrm{H}) ;{ }^{13} \mathrm{C}$ NMR (125 MHz, $\mathrm{CD}_{3} \mathrm{OD}, \delta$ (ppm)): 64.2, 67.9, 70.2, 70.5, 77.6, 81.2, 170.8; IR (thin film, $\mathrm{cm}^{-1}$ ): 3326, 2872, 1752, 1204, 1110; GPC (THF: $1 \mathrm{~mL} \mathrm{~min}{ }^{-1}$ ): $M_{\mathrm{w}}=9258 \mathrm{~g} \mathrm{~mol}^{-1}, M_{\mathrm{n}}=7893 \mathrm{~g}$ $\mathrm{mol}^{-1}$, PDI $=1.17$.

2.3.2. Procedure for synthesis of copolymer 4. Anhydrous $\mathrm{K}_{2} \mathrm{CO}_{3}$ (204 mg, 2.2 equivalent) and decanoyl chloride (280 mg, $0.30 \mathrm{~mL}, 2.2$ equivalent) were added under nitrogen atmosphere to a solution of poly[1,6-di-O-(polyoxyethylene-oxy-bis(carboxymethyl))-2,5-anhydro-D-mannitol] (3, $500 \mathrm{mg}$ ) in dichloromethane $(10 \mathrm{~mL})$. The reaction mixture was stirred for $15 \mathrm{~h}$ at $40{ }^{\circ} \mathrm{C}$. After completion, the reaction mixture was filtered off and the solvent was evaporated under reduced pressure. The crude product thus obtained was washed with hexane $(2 \times 20$ $\mathrm{mL})$ and diethyl ether $(2 \times 20 \mathrm{~mL})$ to afford the pure amphiphilic copolymer 4 .

Copolymer 4 was obtained as viscous oil in $80 \%$ yield; ${ }^{1} \mathrm{H}$ NMR (500 MHz, $\left.\mathrm{CDCl}_{3}, \delta(\mathrm{ppm})\right): 0.82(\mathrm{t}, J=7.1 \mathrm{~Hz}, 3.4 \mathrm{H}), 1.21-$ $1.23(\mathrm{~m}, 15 \mathrm{H}), 1.54-1.57(\mathrm{~m}, 2 \mathrm{H}), 2.29(\mathrm{t}, J=7.4 \mathrm{~Hz}, 2 \mathrm{H}), 3.59-$ $3.69(\mathrm{~m}, 44 \mathrm{H}), 4.10-4.15(\mathrm{~m}, 4 \mathrm{H}), 4.18-4.34$ (m, 4H), 5.06-5.19 $(\mathrm{m}, 1.1 \mathrm{H}) ;{ }^{13} \mathrm{C}$ NMR $\left(125 \mathrm{MHz}, \mathrm{CDCl}_{3}, \delta(\mathrm{ppm})\right): 14.1,22.7,24.7$, 29.0, 29.2 , 29.3 , 29.4, 31.8, 33.9, 63.2, 68.3, 68.6, 70.6, 70.9, 77.8, 81.2, 170.2, 172.7; IR (thin film, $\mathrm{cm}^{-1}$ ): 3491, 2923, 2868, 1744, 1350, 1248, 1111, 950, 849; GPC (THF: $\left.1 \mathrm{~mL} \min ^{-1}\right): M_{\mathrm{w}}=$ $9200 \mathrm{~g} \mathrm{~mol}^{-1}, M_{\mathrm{n}}=5757 \mathrm{~g} \mathrm{~mol}^{-1}$, PDI $=1.59$.

2.3.3. Procedure for synthesis of copolymer 5. Anhydrous $\mathrm{K}_{2} \mathrm{CO}_{3}$ (284 mg, 3.2 equivalent) and myristoyl chloride $(0.55 \mathrm{~mL}$, 3.2 equivalent) were added under nitrogen atmosphere to a solution of poly[1,6-di-O-(polyoxyethylene-oxy-bis(carboxymethyl))-2,5-anhydro-D-mannitol] (3, $480 \mathrm{mg}$ ) in dichloromethane $(30 \mathrm{~mL})$. The reaction mixture was stirred for $15 \mathrm{~h}$ at $40{ }^{\circ} \mathrm{C}$. After completion, the reaction mixture was filtered off and the solvent was evaporated under reduced pressure. The crude product thus obtained was washed with hexane $(2 \times 20$ $\mathrm{mL})$ and diethyl ether $(2 \times 20 \mathrm{~mL})$ to afford the pure amphiphilic copolymer 5 .

Copolymer 5 was obtained as viscous oil in $76 \%$ yield; ${ }^{1} \mathrm{H}$ NMR (500 MHz, $\left.\mathrm{CDCl}_{3}, \delta(\mathrm{ppm})\right): 0.85(\mathrm{t}, J=6.7 \mathrm{~Hz}, 3.2 \mathrm{H}), 1.22-$ $1.25(\mathrm{~m}, 22 \mathrm{H}), 1.56-1.59(\mathrm{~m}, 2 \mathrm{H}), 2.30(\mathrm{t}, J=7.1 \mathrm{~Hz}, 2 \mathrm{H}), 3.61-$ $3.71(\mathrm{~m}, 44 \mathrm{H}), 4.14-4.28(\mathrm{~m}, 8 \mathrm{H}), 5.08-5.20(\mathrm{~m}, 1.1 \mathrm{H}) ;{ }^{13} \mathrm{C} \mathrm{NMR}$ (125 $\mathrm{MHz}, \mathrm{CDCl}_{3}, \delta$ (ppm)): 14.1, 22.7, 24.7, 29.0, 29.2, 29.3, 29.4, 29.6, 29.7, 31.9, 33.9, 63.1, 68.3, 68.6, 70.5, 70.9, 77.8, 81.2, 170.1, 170.9, 172.7; IR (thin film, $\mathrm{cm}^{-1}$ ): 3512, 2922, 2854, 1753, 1461, 1350, 1249, 1198, 1113, 950, 849; GPC (THF: $1 \mathrm{~mL} \mathrm{~min}^{-1}$ ): $M_{\mathrm{w}}=5239 \mathrm{~g} \mathrm{~mol}^{-1}, M_{\mathrm{n}}=4264 \mathrm{~g} \mathrm{~mol}^{-1}, \mathrm{PDI}=1.22$.

2.3.4. Procedure for synthesis of copolymer 6. PEG-1000 diethyl ester (1.57 g) and 2,5-anhydro-3,4-di-O-benzyl-Dmannitol $(2,500 \mathrm{mg})$ were placed in a $50 \mathrm{~mL}$ round-bottom flask and stirred at $70{ }^{\circ} \mathrm{C}$ for $5 \mathrm{~min}$ to make the homogenous mixture. Novozym 435 (207 mg, 10\% by weight of monomers) was added to this mixture and reaction flask was maintained at $70{ }^{\circ} \mathrm{C}$ under vacuum. The reaction was allowed to proceed for $48 \mathrm{~h}$, after which the reaction was quenched by adding chloroform 
and filtering off the enzyme. The organic phase was dialyzed in the dialysis tube against chloroform for $48 \mathrm{~h}$ to afford the pure amphiphilic copolymer 6.

Copolymer 6 was obtained as viscous oil in $72 \%$ yield; ${ }^{1} \mathrm{H}$ NMR (500 MHz, $\left.\mathrm{CDCl}_{3}, \delta(\mathrm{ppm})\right): 1.26(\mathrm{t}, J=7.1 \mathrm{~Hz}, 3 \mathrm{H}), 3.61-$ $3.69(\mathrm{~m}, 891 \mathrm{H}), 3.97$ (d, $J=1.7 \mathrm{~Hz}, 20 \mathrm{H}), 4.11-4.14(\mathrm{~m}, 49 \mathrm{H})$, 4.17-4.22 (m, 48H), 4.24-4.26 (m, 24H), 4.50-4.53 (m, 48H), 7.27-7.35 (m, 134H); ${ }^{13} \mathrm{C} \mathrm{NMR} \mathrm{(125} \mathrm{MHz,} \mathrm{CDCl}_{3}, \delta$ (ppm)): 64.1, 68.4, 70.5, 70.9, 72.0, 80.9, 84.0, 127.8, 128.1, 128.5, 128.6, 137.2, 170.2; IR (thin film, $\mathrm{cm}^{-1}$ ): 2872, 1751, 1455, 1350, 1250, 1205, 1105, 950, 849; GPC (THF: $1 \mathrm{~mL} \mathrm{~min}{ }^{-1}$ ): $M_{\mathrm{w}}=14987 \mathrm{~g} \mathrm{~mol}^{-1}$, $M_{\mathrm{n}}=12485 \mathrm{~g} \mathrm{~mol}^{-1}$, PDI $=1.20$.

2.3.5. Procedure for synthesis of copolymer 7. PEG-600 diethyl ester (389 mg) and 2,5-anhydro-3,4-di-O-benzyl-Dmannitol $(2,200 \mathrm{mg})$ were placed in a $50 \mathrm{~mL}$ round-bottom flask and stirred at $70{ }^{\circ} \mathrm{C}$ for $5 \mathrm{~min}$ to make the homogenous mixture. Novozym 435 ( $58.9 \mathrm{mg}, 10 \%$ by weight of monomers) was added to this mixture and reaction flask was maintained at $70{ }^{\circ} \mathrm{C}$ under vacuum. The reaction was allowed to proceed for $48 \mathrm{~h}$ and quenched upon completion by adding chloroform and filtering off the enzyme. The organic phase was dialyzed in the dialysis tube against chloroform for $48 \mathrm{~h}$ to afford the pure copolymer 7.

Copolymer 7 was obtained as viscous oil in $77 \%$ yield; ${ }^{1} \mathrm{H}$ NMR (400 MHz, $\left.\mathrm{CDCl}_{3}, \delta(\mathrm{ppm})\right): 1.24$ (t, $\left.J=7.0 \mathrm{~Hz}, 3 \mathrm{H}\right), 3.59-$ 3.66 (m, 567H), 3.91 (bs, 22H), 4.09-4.11 (m, 44H), 4.15-4.22 (m, 60H), 4.48-4.51 (m, 42H), 7.24-7.33 (m, 124H); ${ }^{13} \mathrm{C}$ NMR (100.6 MHz, $\mathrm{CDCl}_{3}, \delta$ (ppm)): 64.2, 68.4, 70.6, 71.0, 72.1, 80.9, 84.1, 127.8, 128.1 128.6, 137.2, 170.2; GPC (THF: $1 \mathrm{~mL} \mathrm{~min}^{-1}$ ): $M_{\mathrm{w}}=10573 \mathrm{~g} \mathrm{~mol}^{-1}, M_{\mathrm{n}}=8502 \mathrm{~g} \mathrm{~mol}^{-1}, \mathrm{PDI}=1.24$.

\subsection{ICG encapsulation in sugar-PEG-based copolymeric micelles}

The film method was implemented to encapsulate ICG within micelles. For encapsulation, a $0.25 \mathrm{mM}$ stock solution of ICG was prepared by dissolving $2 \mathrm{mg}$ of the dye in $10 \mathrm{~mL}$ of dry dichloromethane. Aliquots $(100 \mu \mathrm{L})$ were added to $5 \mathrm{~mL}$ vials and the solvent was allowed to evaporate. Additionally, an aqueous solution of copolymers $\left(10 \mathrm{mg} \mathrm{mL}^{-1}\right)$ that had been stirred for $2 \mathrm{~h}$ was added to a sample vial containing ICG. The solutions were stirred overnight, after which a dialysis against water was done to remove the excess ICG. In the end, ICGloaded aqueous micellar solutions of copolymer 4, 5, and 6 were afforded.

\subsection{ICG encapsulation efficiency and loading capacity}

To determine the encapsulation efficiency (EE) of ICG and loading capacity (LC) of micelles, sugar-PEG-based copolymer (10 mg) and ICG (1 mg) were dissolved in DMSO (3 mL) at room temperature. ${ }^{18}$ The mixture was dialyzed with a dialysis tube against water for 3 days. A certain volume of the dialyzed encapsulated ICG solution was diluted 20 times with DMSO to destroy the micelles. The concentration of ICG in a diluted solution was determined by comparing the absorbance at $780 \mathrm{~nm}$ to a standard curve of ICG within a linear range of 0-10 $\mu \mathrm{M}$ in DMSO. The EE and LC were determined according to the following formulas:

$\mathrm{EE}(\%)=($ weight of encapsulated ICG/ weight of initially added ICG) $\times 100$.

LC $(\%)=($ weight of encapsulated ICG/ total weight of ICG and copolymer) $\times 100$.

\subsection{Nile red encapsulation protocol}

For encapsulation of Nile red, a $5 \mathrm{mM}$ stock solution of Nile red was prepared by dissolving $1.59 \mathrm{mg}$ of Nile red in $1 \mathrm{~mL}$ of dry dichloromethane. A small aliquot $(200 \mu \mathrm{L})$ from the stock solution was added to the sample vial and the solvent was allowed to evaporate. Additionally, an aqueous solution of copolymer $(8 \mathrm{mg}$ ) was first stirred for $2 \mathrm{~h}$ and then added to the sample vial with the Nile red. The solutions were allowed to stir overnight, which was followed by filtration to remove the nonencapsulated Nile red dye.

\subsection{Cytotoxicity protocol}

The xCELLigence real-time cell analyzer (RTCA) SP from Roche (Mannheim, Germany) was used to investigate the cytotoxicity of all the synthesized copolymers. A549 cells grown on a 96 well E-plate were placed in the RTCA. The impedance was measured every $15 \mathrm{~min}$. After $24 \mathrm{~h}$, the plate was removed from the RTCA, and three water-soluble copolymers were added at final concentrations of 10,100 , and $500 \mu \mathrm{g} \mathrm{mL}{ }^{-1}$. The non-treated and doxorubicin-treated cells were used for the control experiment. The plate was replaced in the RTCA and real time impedance measurements was continued for another $72 \mathrm{~h}$. GraphPad prism 5.01 software was used to plot the analysis of the end points obtained from the RTCA after 24,48 , and $72 \mathrm{~h}$ post-treatment.

\subsection{Cellular uptake protocol}

Briefly, $0.2-0.3 \times 10^{-6}$ cells per well were placed in a 12 well plate and allowed to attach overnight. To assess the cellular uptake of encapsulated micelles, the growth medium was completely replaced with the serum and an antibiotic-free medium that contained Nile red-loaded polymeric micelles at

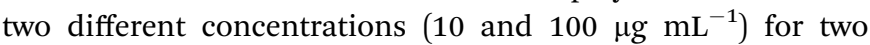
different time points ( 2 and $4 \mathrm{~h}$ ). For the internalization studies, $0.2 \mathrm{~mL}$ solution was added to each well, which had been prepared from $0.1 \mathrm{~mL}$ of $10 \%$ FBS-DMEM and $0.1 \mathrm{~mL}$ of distilled water with Nile red-loaded fluorescent polymeric micelles that led to the respective final micelle concentrations. After the desired incubation period, the cells were washed three times with ice-cold PBS and then incubated for $20 \mathrm{~min}$ with DAPI (360 $\pm 20 \mathrm{~nm}$ and $460 \pm 25 \mathrm{~nm}$, blue channel). Cells that were incubated in the media alone without any formulations served as the negative control for auto-fluorescence. At the end of each time period, the cells were washed, fixed (using 4\% paraformaldehyde), and examined under a confocal microscope. 


\section{Results and discussion}

\subsection{Synthesis of sugar-PEG-based copolymers 3-7 and its characterization}

During the transesterification reaction, some of the lipases like Candida antarctica lipase recognized a primary hydroxyl group over the secondary hydroxyl group. ${ }^{32}$ The copolymerization of 2,5-anhydro-D-mannitol (1) and poly[ethylene glycol bis(carboxymethyl)ether]diethyl ester (PEG-600 diethyl ester) was achieved by transesterification reaction catalyzed by Candida antarctica lipase B immobilized on polyacrylate (Lewatite), commonly known as Novozym 435 under solvent-free conditions. Thus, Novozym 435 was added to the homogeneous mixture of PEG-600 diethyl ester and 2,5-anhydro-D-mannitol (1) at $70{ }^{\circ} \mathrm{C}$; the mixture was stirred for $48 \mathrm{~h}$ under reduced pressure to obtain the dihydroxy copolymer 3 in $70 \%$ yield (Scheme 1). The PEG-600 diethyl ester and the 2,5-anhydro-Dmannitol (1) were prepared from PEG-600 and ethanol under acidic condition and from $\mathrm{D}$-glucosamine, respectively by following a literature procedure. ${ }^{33-35}$ The post-polymerization functionalization of copolymer 3 , i.e. its acylation with decanoyl chloride and myristoyl chloride was done in dichloromethane in the presence of potassium carbonate base to obtain decanoylated and myristoylated copolymers 4 and 5 in $80 \%$ and $76 \%$ yields, respectively. The study of ${ }^{1} \mathrm{H}$ NMR spectra of copolymers 4 and 5 revealed 50-55\% installation of acyl group on the secondary hydroxyl groups of dihydroxy copolymer 3 . The reaction of 2,5-anhydro-D-mannitol (1) with PEG 1000 diethyl ester $^{36}$ under the developed bulk reaction condition formed a gel (crosslinked product), which was not soluble in any solvent and therefore was not used for further studies. The copolymers 6 and 7 were prepared under solvent free conditions at $70^{\circ} \mathrm{C}$ by Novozym 435-catalyzed transesterification reaction of 2,5anhydro-3,4-di-O-benzyl-D-mannitol (2) with PEG-1000 and PEG600 diethyl esters in $72 \%$ and $77 \%$ yields, respectively. Reaction

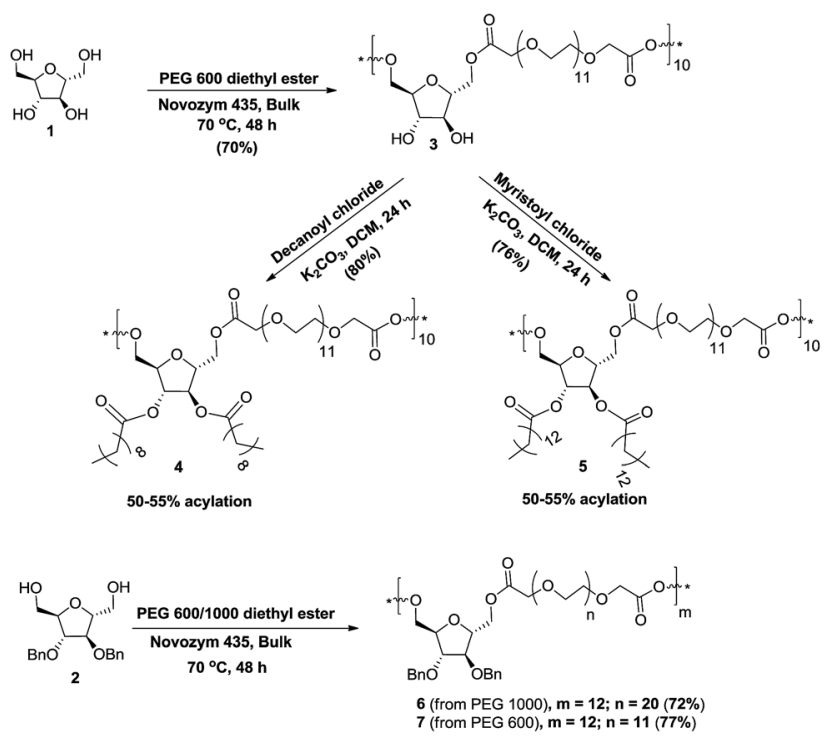

Scheme 1 Synthesis of sugar-PEG based copolymers 3-7. of PEG-1000 diethyl ester with dibenzylated anhydro-mannitol 2 did not form a gel (crosslinked product) as earlier, which may have been due to the masking of the secondary hydroxyl groups of the sugar. The transesterification reaction between dibenzylated anhydro-mannitol 2 and PEG-600 diethyl ester led to the water insoluble copolymer 7, which was not used for further studies (Scheme 1).

All five copolymers 3-7 were well characterized by their IR, ${ }^{1} \mathrm{H}-,{ }^{13} \mathrm{C}-$, DEPT-135, COSY, and HSQC NMR spectral data analysis. The number-average molecular weight $\left(M_{\mathrm{n}}\right)$ for all five copolymers was determined by GPC. The $M_{\mathrm{n}}$ of copolymers 3, 6, and 7 was further confirmed by an end-group analysis by comparing three protons of methyl group of PEG ethyl ester that resonated at $1.26 \mathrm{ppm}$ with protons of polyethylene glycol units in ${ }^{1} \mathrm{H}$ NMR spectra (Table S1, ESI $\dagger$ ). The $M_{\mathrm{n}}$ of copolymers 4 and 5 was not determined by end-group analysis due to the overlapping of protons of acyl chain with the three protons of methyl group of PEG ethyl ester. The $M_{\mathrm{n}}$ determined by GPC and ${ }^{1} \mathrm{H}$ NMR indicated the presence of approximately ten monomeric units in copolymers $3, \mathbf{4}$, and 5 and twelve monomeric units in copolymers 6 and 7.

The integration for three protons of the methyl group of acyl chains resonating at $0.88 \mathrm{ppm}$ in comparison to the 44 protons of polyethylene glycol chain of one repeating unit resonating at $3.62-3.70 \mathrm{ppm}$ clearly indicated $50-55 \%$ acylation of the secondary hydroxyl groups in copolymers $\mathbf{4}$ and $\mathbf{5}$.

\subsection{Aggregation behavior study of copolymers 4-6 in aqueous solution}

Aggregation behavior and size of the aggregates of copolymers 4, 5, and 6 in aqueous solution were investigated by using surface tension and dynamic light scattering measurements, respectively. Surface tension data were plotted as logarithm function of copolymer concentration, where a break in the curve occurred at a critical aggregation concentration (CAC) (Fig. 1).

The CAC values obtained by surface tension measurement for copolymers 4, 5, and 6 are $36.4,16.0$, and $1.0 \mu \mathrm{M}$, respectively (Table 1). The CAC data revealed that the installation of more hydrophobic groups decreased the CAC value. CAC measurements and further studies on copolymers 3 and 7 could not be done, because the former copolymer was not amphiphilic and the latter one was insoluble in water. The size of aggregates of copolymers 4, 5 and 6 was determined by using the dynamic light scattering (DLS) method. The concentration of samples in aqueous solution to determine their size was kept above CAC for all three copolymers 4-6, i.e., $5 \mathrm{mg} \mathrm{mL}^{-1}$ for

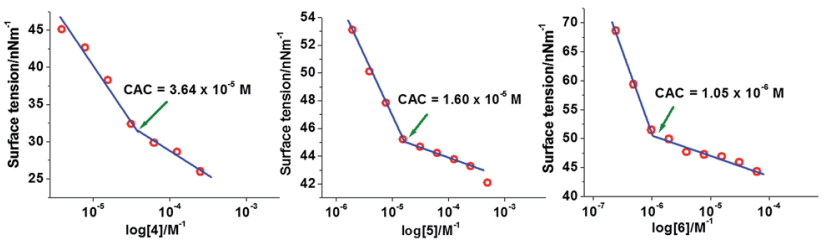

Fig. 1 Surface tension $(\gamma)$ versus log concentration plots of copolymers 4, 5, and 6 in aqueous solution at $20^{\circ} \mathrm{C}$. 
Table 1 Critical aggregation concentration (CAC), DLS size, polydispersity index (PDI) before and after encapsulation of ICG, loading capacity (LC)

\begin{tabular}{|c|c|c|c|c|c|c|}
\hline \multirow[b]{2}{*}{ Polymer } & \multirow[b]{2}{*}{$\mathrm{CAC}(\mu \mathrm{M})$} & \multicolumn{2}{|c|}{$\begin{array}{l}\text { Before ICG } \\
\text { encapsulation }\end{array}$} & \multicolumn{2}{|c|}{$\begin{array}{l}\text { After ICG } \\
\text { encapsulation }\end{array}$} & \multirow[b]{2}{*}{ LC $(\%)$} \\
\hline & & $D_{\mathrm{h}}(\mathrm{nm})$ & PDI & $D_{\mathrm{h}}(\mathrm{nm})$ & PDI & \\
\hline 4 & 36.4 & $10.9 \pm 0.3$ & 0.2 & $11.4 \pm 0.4$ & 0.2 & $5.8 \pm 0.4$ \\
\hline 5 & 16.0 & $13.4 \pm 0.8$ & 0.2 & $20.5 \pm 4.5$ & 0.3 & $8.3 \pm 0.5$ \\
\hline 6 & 1.0 & $219.7 \pm 4.9$ & 0.3 & $1267 \pm 96.9$ & 0.7 & $1.8 \pm 0.2$ \\
\hline
\end{tabular}

copolymers 4 and 5 and $2 \mathrm{mg} \mathrm{mL} \mathrm{m}^{-1}$ for copolymer 6 . The hydrodynamic diameters of copolymers $\mathbf{4}, \mathbf{5}$, and $\mathbf{6}$ determined by DLS were found to be $10.9 \pm 0.3,13.4 \pm 0.8$, and $219.7 \pm$ $4.9 \mathrm{~nm}$, respectively (Fig. S19, ESI†). The DLS data showed that the size of micelles rose with the increase of hydrophobic character in the copolymers. The particle size of ICG-loaded micelles was also investigated by DLS and observed that the size of the micelles of copolymer $\mathbf{4}$ and $\mathbf{5}$ slightly increased after encapsulation of ICG but the size of micellar aggregates of copolymer 6 dramatically increased to $1.2 \mu \mathrm{m}$ after encapsulation of ICG (Table 1). The morphology of micelles derived from copolymers 4,5 , and $\mathbf{6}$ in aqueous medium was determined by transmission electron microscope (TEM). The TEM analysis of copolymers 4 and $\mathbf{5}$ showed the hydrodynamic diameter of $9.0 \pm 1.0 \mathrm{~nm}$ and $15.5 \pm 1.0 \mathrm{~nm}$, respectively (Table 1). The TEM images revealed uniform small micelles for copolymers $\mathbf{4}$ and $\mathbf{5}$. The TEM images of the supramolecular structure for the copolymer 6 revealed that the size of the aggregates was $50 \pm 5 \mathrm{~nm}$, which indicated that micelle aggregates had formed. Furthermore, the TEM images of the distribution of micellar aggregates of copolymer 6 were not uniform (Fig. 2).

\subsection{Study of encapsulation of ICG by copolymers 4-6}

ICG has extensively been used in PTT, PDT, and tumor localization studies in-spite of the fact that it quickly degrades in aqueous medium..$^{37-40}$ The first step towards developing a nanoformulation for sustainable delivery of the ICG in physiological condition was to encapsulate the dye in the micelles and micellar aggregates of copolymers 4,5 , and 6 . The aqueous solutions of ICG-encapsulated micelles of copolymers $\mathbf{4}, \mathbf{5}$, and 6 were then analyzed by a UV-visible and fluorescence spectrophotometer. The $\lambda_{\max }$ of UV-visible spectrum of free ICG taken in Milli-Q water was $780 \mathrm{~nm}$. The $\lambda_{\max }$ of UV-visible spectra of ICG encapsulated in copolymers 4, 5, and 6 exhibited bathochromic shifts at 795, 798, and $792 \mathrm{~nm}$, respectively (Fig. 3A). The $\lambda_{\max }$ of emission in the fluorescence spectrum of an aqueous solution of ICG was observed at $802 \mathrm{~nm}$. Bathochromic shifts of 26, 24, and $8 \mathrm{~nm}$ were observed when the fluorescence emission spectra of ICG encapsulated in micelles/micellar aggregates that had been derived from copolymers $\mathbf{4}, \mathbf{5}$ and $\mathbf{6}$, respectively were recorded (Fig. 3B). These bathochromic shifts clearly indicated that ICG had been encapsulated in micelles/ micellar aggregates of copolymers 4, 5, and $\mathbf{6}$, which afforded the nanoformulation. Both the absorbance and fluorescence

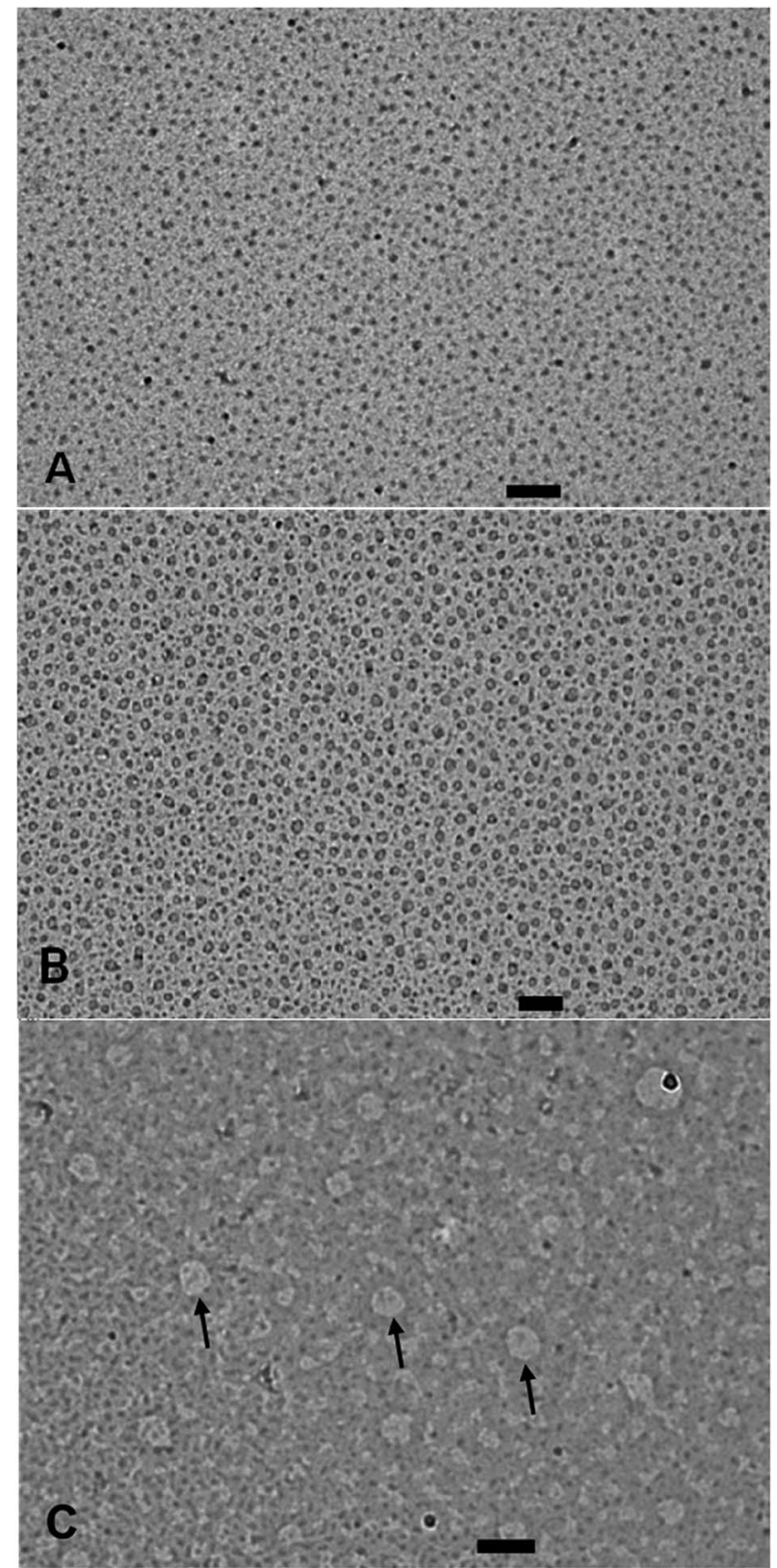

Fig. 2 TEM images of micelles/micellar aggregates of copolymer 4 (A), copolymer 5 (B), and copolymer 6 (C) with a scale bar of $100 \mathrm{~nm}$.

spectra revealed that the micellar aggregates derived from copolymer 6 had considerably less encapsulation.

\subsection{ICG loading and aqueous stability of the formulation}

The ICG-loading efficiency in micelles/micellar aggregates of copolymers 4, 5, and 6 were determined with the help of a standard curve obtained from plotting the absorbance of the solution of different concentrations of ICG in DMSO. The ICG encapsulation efficiency in the micelles formed by copolymers 4 and 5 was much higher (62 and 92\%) than the micellar aggregate formed by copolymer 6 (19\%). The loading capacities of micelles obtained from copolymers 4 and 5 were 5.8 and 8.3\%, 

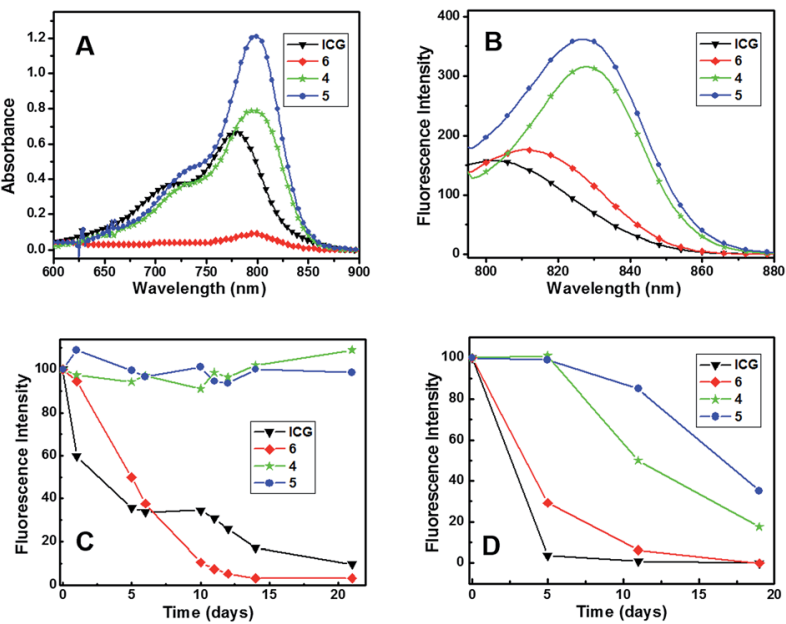

Fig. 3 (A) UV-visible, (B) emission spectra, (C) fluorescence stability test at $20{ }^{\circ} \mathrm{C}$, (D) fluorescence stability test at $37{ }^{\circ} \mathrm{C}$ of free ICG and encapsulated ICG in copolymers 4, 5, and 6.

respectively, which was far better than the micellar aggregates formed by copolymer $6(1.8 \%)$.

To compare the stability of ICG encapsulated in micelles/ micellar aggregates of copolymers 4,5 , and 6 with native ICG dissolved in aqueous solution, the fluorescence intensity of the encapsulated and the native ICG was recorded for a period of 21 days at $20{ }^{\circ} \mathrm{C}$ and 19 days at $37{ }^{\circ} \mathrm{C}$. It was revealed that nanoformulated ICG had better fluorescence stabilization while free ICG lost approximately 50\% fluorescence intensity in $24 \mathrm{~h}$ and had only $5 \%$ after 3 weeks at $20^{\circ} \mathrm{C}$ (Fig. 3C). The formulation of ICG with copolymer 6 showed better stabilization up to 2 days but rapidly lost the fluorescence after that and had only $2 \%$ after 3 weeks at $20{ }^{\circ} \mathrm{C}$. However, the nanoformulation in micelles derived from copolymers $\mathbf{4}$ and $\mathbf{5}$ had better fluorescence stabilization, because approximately $100 \%$ fluorescence intensity was retained, even after 3 weeks, at $20^{\circ} \mathrm{C}$. DLS showed that the size of ICG-encapsulated micelles of copolymer 6 increased many times and no particle size was observed after 5 days, which indicated that the ICG-loaded micelles of copolymer $\mathbf{6}$ were not stable. However, the size of ICG encapsulated in the micelles of copolymers $\mathbf{4}$ and $\mathbf{5}$ showed little change in size, even on the 5th day; these micelles were thus stable and remained intact during the experiment.

Fluorescence intensity measurements of native ICG and its nanoformulation in micelles/micellar aggregates of copolymers 4,5 , and 6 at $37{ }^{\circ} \mathrm{C}$ revealed the native dye degraded up to $97 \%$ and the dye in the micellar aggregates of copolymer $\mathbf{6}$ decreased to $70 \%$ within 5 days (Fig. 3D). ICG encapsulated in the micelles of copolymers 4 and 5 exhibited almost 100\% stability for 5 days. Comparing the fluorescence intensity beyond 5 days revealed that ICG-loaded micelles of copolymer $\mathbf{5}$ were more stable than copolymer 4 . Thus, there was only $10 \%$ loss of the ICG encapsulated in the micelles of copolymer 5, whereas ICG in micelles of copolymer 4 lost its $50 \%$ fluorescence on the 11th day. About $40 \%$ fluorescence of ICG remained in the micelles of copolymer 5 after 19 days compared to $20 \%$ activity in the micelles of copolymer 4 (Fig. 3D). This shows that micelles of sugar-PEG copolymer with longer C14 acyl chains were more stable than the one with C10 acyl chains.

\subsection{In vitro cytotoxicity assay}

A good carrier should be non-toxic to cells. Therefore, the cytotoxicity of three micelles/micellar aggregates of sugar-PEGbased copolymers 4,5 , and 6 was investigated by real-time cell analysis using A549 cells for $72 \mathrm{~h}$. All the copolymers showed good compatibility, because the cell viability was observed to be above $80 \%$, even after $72 \mathrm{~h}$ of incubation up to a concentration of $500 \mu \mathrm{g} \mathrm{mL} \mathrm{m}^{-1}$ for copolymers 5 and $\mathbf{6}$ and up to a concentration of $100 \mu \mathrm{g} \mathrm{mL}^{-1}$ for copolymers 4 . For copolymers 4 and $\mathbf{5}$, a concentration-dependent decrease in the cell's viability was monitored indicating a slight toxicity at the higher test concentrations. A time-dependent decrease in the cell's viability to a value below $60 \%$ was detected for copolymer 4 at the highest test concentration of $500 \mu \mathrm{g} \mathrm{mL}^{-1}$ (Fig. 4A). The cytotoxicity of ICG-loaded micelles was also tested using A549 cells for $72 \mathrm{~h}$. The ICG-loaded copolymers 4 and $\mathbf{5}$ showed good compatibility up to the concentration of $100 \mu \mathrm{g} \mathrm{mL}^{-1}$ and the ICG-loaded copolymer 6 showed better compatibility up to a concentration of $500 \mu \mathrm{g} \mathrm{mL} \mathrm{m}^{-1}$ (Fig. 4B).

\subsection{Cellular uptake study of micelles of copolymers 4 and 5}

The cellular internalization of micelles of copolymer 4 and 5 was assessed by incubation of A549 cells with Nile red loaded micelles followed by the measurement of fluorescence intensity of incubated cells. The micellar aggregates of compound 6 were not tested for cellular internalization due to its poor Nile redloading capability. The Nile red loaded micelles of copolymer 4 and 5 indicated the DLS size of $27.1 \pm 2.9$ and $12.5 \pm 1.3 \mathrm{~nm}$,
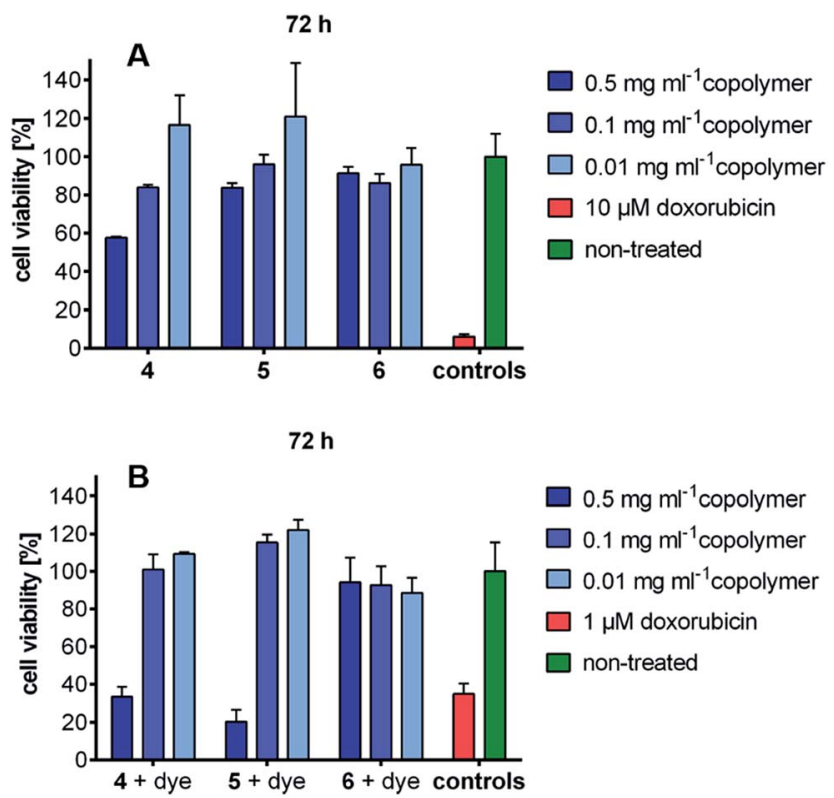

Fig. 4 (A) Cytotoxicity data of copolymers 4, 5, and 6, (B) cytotoxicity data of ICG-loaded copolymers. 
respectively which is comparable with the ICG loaded micelles. The result of confocal images of micelles of copolymer 4 loaded with Nile red showed that $2 \mathrm{~h}$ incubation of cells with $10 \mu \mathrm{g}$ $\mathrm{mL}^{-1}$ of Nile red-loaded micelles had a lower fluorescence intensity than the $4 \mathrm{~h}$ incubation (Fig. 5B and C) of the same micellar solution. But the incubation of cells with $100 \mu \mathrm{g} \mathrm{mL}^{-1}$ of Nile red-encapsulated micellar solution for $2 \mathrm{~h}$ had as much fluorescence intensity as the $4 \mathrm{~h}$ incubation (Fig. 5D and E). This suggests that there was an optimum concentration and time for the cellular uptake of Nile red-encapsulated micellar solution. The micelles of copolymer 5 loaded with Nile red also showed the cellular internalization of Nile red at different time intervals. The fluorescence intensity at a $2 \mathrm{~h}$ incubation of polymeric micelles loaded with Nile red had a weaker intensity than the $4 \mathrm{~h}$ incubation (Fig. 6B and C) at $10 \mu \mathrm{g} \mathrm{mL}^{-1}$ concentration. Similarly, the results of the confocal images showed that the $2 \mathrm{~h}$ incubation of cells at a concentration of $100 \mu \mathrm{g} \mathrm{mL}^{-1}$ had a lower fluorescence intensity than $4 \mathrm{~h}$ incubation (Fig. 6D and E) of cell with $100 \mu \mathrm{g} \mathrm{mL}^{-1}$ Nile red-encapsulated micellar solution.

(A)
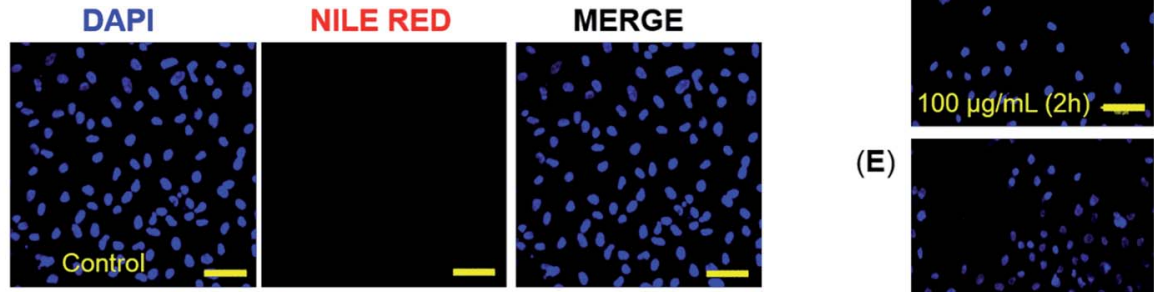

(D)
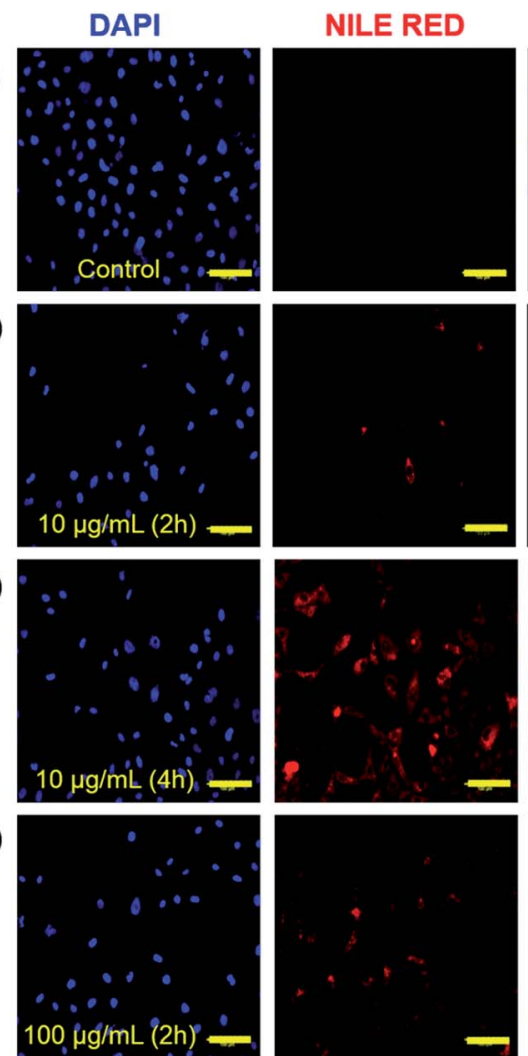

(B)
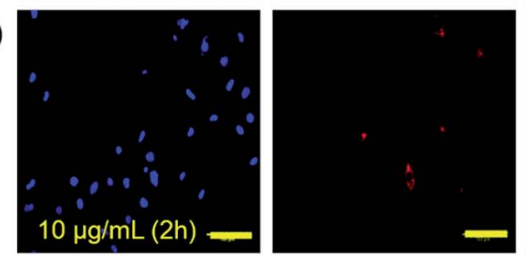

(C)

(E)
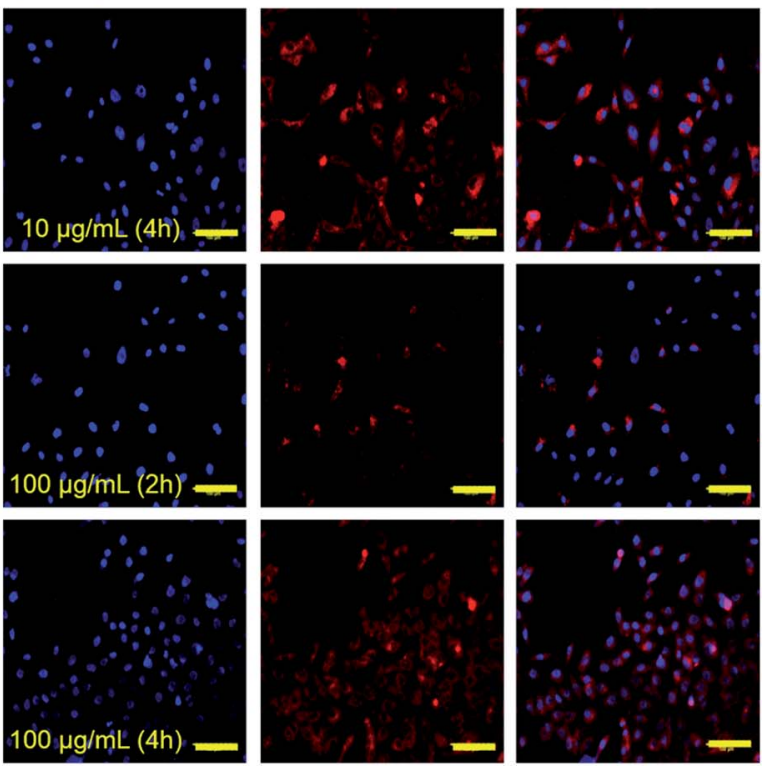

Fig. 6 Confocal laser scanning fluorescence micrograph of A549 cells incubated with 10 and $100 \mu \mathrm{g} \mathrm{mL} \mathrm{m}^{-1}$ concentration of copolymer 5 loaded with Nile red at $2 \mathrm{~h}$ and $4 \mathrm{~h}(\mathrm{~A}-\mathrm{E})$ with a scale bar of $100 \mu \mathrm{m}$.

(C)
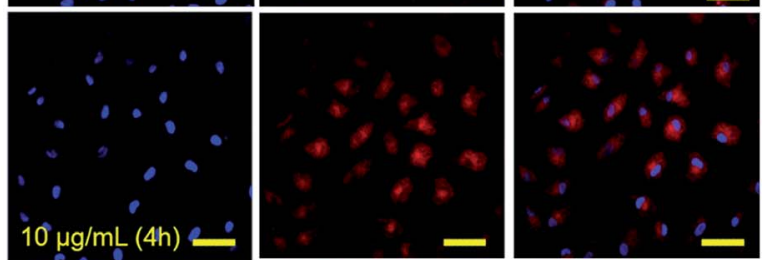

(D)
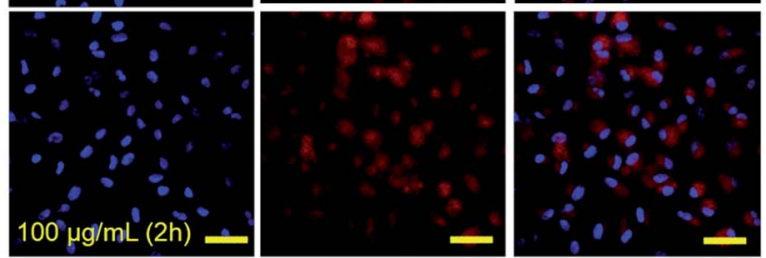

(E)
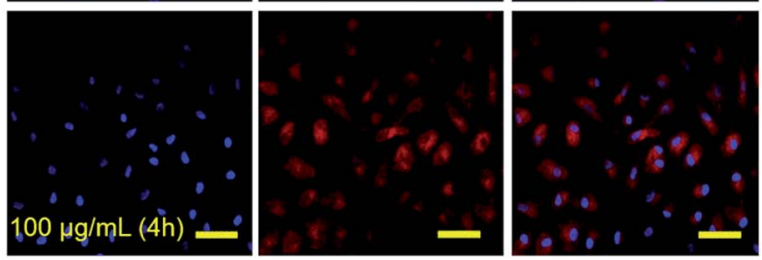

Fig. 5 Confocal laser scanning fluorescence micrograph of A549 cells incubated with 10 and $100 \mu \mathrm{g} \mathrm{mL}^{-1}$ concentration of copolymer 4 loaded with Nile red at $2 \mathrm{~h}$ and $4 \mathrm{~h}(\mathrm{~A}-\mathrm{E})$ with a scale bar of $100 \mu \mathrm{m}$.

\section{Conclusions}

Environment friendly methodology has been developed for the synthesis of five sugar-PEG-based copolymers via Novozym 435mediated transesterification reaction between 2,5-anhydro-Dmannitol/2,5-anhydro-3,4-di-O-benzyl-D-mannitol and PEG-600/ PEG-1000 diethyl ester under bulk conditions. It has been discovered that three water-soluble amphiphilic copolymers form micelles and micellar aggregates in aqueous conditions. In particular, two micelles derived from acylated amphiphilic copolymers $\mathbf{4}$ and $\mathbf{5}$ encapsulated the dye indocyanine green (ICG) $62 \%$ and 92\%, respectively. Furthermore, micellar solutions of copolymers $\mathbf{4}$ and $\mathbf{5}$ efficiently stabilized the encapsulated ICG for 21 days at $20{ }^{\circ} \mathrm{C}$ and 5 days at $37{ }^{\circ} \mathrm{C}$. The two micelles that efficiently encapsulated ICG also exhibited good cellular uptake, which was demonstrated by incubating A549 cells with Nile red-encapsulated micelles. Since these amphiphilic copolymers were not toxic, they can be used to develop a suitable drug carrier agent. 


\section{Acknowledgements}

We gratefully acknowledge the financial support from the IndoGerman Science and Technology Centre (IGSTC), Gurugram, and University of Delhi for providing financial support under DU-DST Purse grant for strengthening research and development. We are also thankful to the CIF-USIC, University of Delhi, for providing the NMR spectral and HRMS recording facilities. V. K. thanks CSIR, New Delhi, for the award of Junior/ Senior research fellowships.

\section{Notes and references}

1 L. Cheng, C. Wang, L. Feng, K. Yang and Z. Liu, Chem. Rev., 2014, 114, 10869.

2 A. Topete, M. A. Meda, P. Iglesias, E. M. Villar-Alvarez, S. Barbosa, J. A. Costoya, P. Taboada and V. Mosquera, ACS Nano, 2014, 8, 2725.

3 A. Yuan, X. Tang, X. Qiu, K. Jiang, J. Wu and Y. Hu, Chem. Commun., 2015, 51, 3340.

4 Z. Sheng, D. Hu, M. Xue, M. He, P. Gong and L. Cai, NanoMicro Lett., 2013, 5, 145.

5 A. K. Kirchherr, A. Briel and K. Mader, Mol. Pharmaceutics, 2009, 6, 480.

6 Y. Chen and X. Li, Biomacromolecules, 2011, 12, 4367.

7 W. H. Jian, T. W. Yu, C. J. Chen, W. C. Huang, H. C. Chiu and W. H. Chiang, Langmuir, 2015, 31, 6202.

8 X. Tan, J. Wang, X. Pang, L. Liu, Q. Sun, Q. You, F. Tan and N. Li, ACS Appl. Mater. Interfaces, 2016, 8, 34991.

9 J. Yu, M. A. Yaseen, B. Anvari and M. S. Wong, Chem. Mater., 2007, 19, 1277.

10 M. Cao, P. Wang, Y. Kou, J. Wang, J. Liu, Y. Li, J. Li, L. Wang and C. Chen, ACS Appl. Mater. Interfaces, 2015, 7, 25014.

11 Y. Zheng, D. Zhang, M. Wu, Y. Liu, X. Zhang, L. Li, Z. Li, X. Han, X. Wei and X. Liu, ACS Appl. Mater. Interfaces, 2014, 6, 14266.

12 Y. Li, T. Wen, R. Zhao, X. Liu, T. Ji, H. Wang, X. Shi, J. Shi, J. Wei, Y. Zhao, X. Wu and G. Nie, ACS Nano, 2014, 8, 11529.

13 M. Liong, J. Lu, M. Kovochich, T. Xia, S. G. Ruehm, A. E. Nel, F. Tamanoi and J. I. Zink, ACS Nano, 2008, 2, 889.

14 K. Deng, Z. Hou, X. Deng, P. Yang, C. Li and J. Lin, Adv. Funct. Mater., 2015, 25, 7280.

15 L. Jing, J. Shi, D. Fan, Y. Li, R. Liu, Z. Dai, F. Wang and J. Tian, ACS Appl. Mater. Interfaces, 2015, 7, 22095.

16 L. Han, Y. Zhang, X. W. Chen, Y. Shu and J. H. Wang, J. Mater. Chem. B, 2016, 4, 105.

17 T. H. Kim, C. W. Mount, B. W. Dulken, J. Ramos, C. J. Fu, H. A. Khant, W. Chiu, W. R. Gombotz and S. H. Pun, Mol. Pharmaceutics, 2012, 9, 135.
18 L. Wu, S. Fang, S. Shi, J. Deng, B. Liu and L. Cai, Biomacromolecules, 2013, 14, 3027.

19 M. Zheng, P. Zhao, Z. Luo, P. Gong, C. Zheng, P. Zhang, C. Yue, D. Gao, Y. Ma and L. Cai, ACS Appl. Mater. Interfaces, 2014, 6, 6709.

20 A. Zhu, K. Miao, Y. Deng, H. Ke, H. He, T. Yang, M. Guo, Y. Li, Z. Guo, Y. Wang, X. Yang, Y. Zhao and H. Chen, ACS Nano, 2015, 9, 7874.

21 R. Gref, Y. Minamitake, M. T. Peracchia, V. Trubetskoy, V. Torchilin and R. Langer, Science, 1994, 263, 1600.

22 K. Yasugi, Y. Nagasaki, M. Kato and K. Kataoka, J. Controlled Release, 1999, 62, 89.

23 R. Savic, L. B. Luo, A. Eisenberg and D. Maysinger, Science, 2003, 300, 615.

24 C. Deng, Y. Jiang, R. Cheng, F. Meng and Z. Zhong, Nano Today, 2012, 7, 467.

25 Z. Liu, Y. Jiao, Y. Wang, C. Zhou and Z. Zhang, Adv. Drug Delivery Rev., 2008, 60, 1650.

26 S. Bhatia, A. Mohr, D. Mathur, V. S. Parmar, R. Haag and A. K. Prasad, Biomacromolecules, 2011, 12, 3487.

27 Y. Zhang, J. W. Chan, A. Moretti and K. E. Uhrich, J. Controlled Release, 2015, 219, 355.

28 J. A. Galbis, M. G. Garcia-Martin, M. V. de Paz and E. Galbis, Chem. Rev., 2016, 116, 1600.

29 Y. Nagasaki, K. Yasugi, Y. Yamamoto, A. Harada and K. Kataoka, Biomacromolecules, 2001, 2, 1067.

30 B. Pandey, J. Mahato, K. B. Cotta, S. Das, D. K. Sharma, S. S. Gupta and A. Chowdhury, ACS Omega, 2016, 1, 600.

31 J. Khandare, M. Calderon, N. M. Dagia and R. Haag, Chem. Soc. Rev., 2012, 41, 2824.

32 J. Maity, G. Shakya, S. K. Singh, V. T. Ravikumar, V. S. Parmar and A. K. Prasad, J. Org. Chem., 2008, 73, 5629.

33 S. Gupta, M. K. Pandey, K. Levon, R. Haag, A. C. Watterson, V. S. Parmar and S. K. Sharma, Macromol. Chem. Phys., 2010, 211, 239.

34 D. Horton and K. D. Philips, Carbohydr. Res., 1973, 30, 367. 35 M. Chaumontet, V. Pons, K. Marotte and J. Prandi, Tetrahedron Lett., 2006, 47, 1113.

36 M. Kumari, A. K. Singh, S. Kumar, K. Achazi, S. Gupta, R. Haag and S. K. Sharma, Polym. Adv. Technol., 2014, 25, 1208.

37 J. Yu, D. Javier, M. A. Yaseen, N. Nitin, R. R. Kortum, B. Anvari and M. S. Wong, J. Am. Chem. Soc., 2010, 132, 1929.

38 L. Cheng, C. Wang, L. Feng, K. Yang and Z. Liu, Chem. Rev., 2014, 114, 10869.

39 B. Zheng, H. Chen, P. Zhao, H. Pan, X. Wu, X. Gong, H. Wang and J. Chang, ACS Appl. Mater. Interfaces, 2016, 8, 21603.

40 N. Li, T. Li, C. Hu, X. Lei, Y. Zuo and H. Han, ACS Appl. Mater. Interfaces, 2016, 8, 15013. 